\title{
Europe contemplates stricter language proficiency testing of doctors
}

$\mathrm{E}$ uropean nations may be creeping toward the imposition of tougher language proficiency requirements for doctors who'd like to hang up a shingle anywhere but their homeland.

Patient and employer complaints about foreign doctors who lack proficiency in a country's official language are prompting a reconsideration of language requirements for doctors seeking to practise within the European Economic Area, which includes all 27 European Union member states, along with Norway, Iceland and Liechtenstein.

The European Commission is now conducting consultations on revisions to the existing Professional Qualifications Directive and plans to issue an updated version in 2012.

The exercise is broadly aimed at determining whether Europe-wide credentialing and harmonized training is necessary to allow for the free movement of professionals. Among measures under consideration are the creation of a "European professional card" and common curricula, complete with minimum training requirements (http://ec.europa .eu/internal_market/consultations/docs /2011/professional_qualifications/consult ation_paper_en.pdf).

The issue of language skills has arisen strictly in the context of health care, the consultation paper adds. "Language requirements should be justified and proportionate, in view of the activity that the professional wishes to carry out. Thus, they may vary according to the activities to be exercised, in line with the proportionality principle. Professionals should be able to demonstrate their linguistic skills by any means (attendance of language training, stay in a country where the language is used, etc.). On the other hand, the Directive should not be construed as imposing a blanket ban on language testing. It does allow for language testing in exceptional and justified cases."

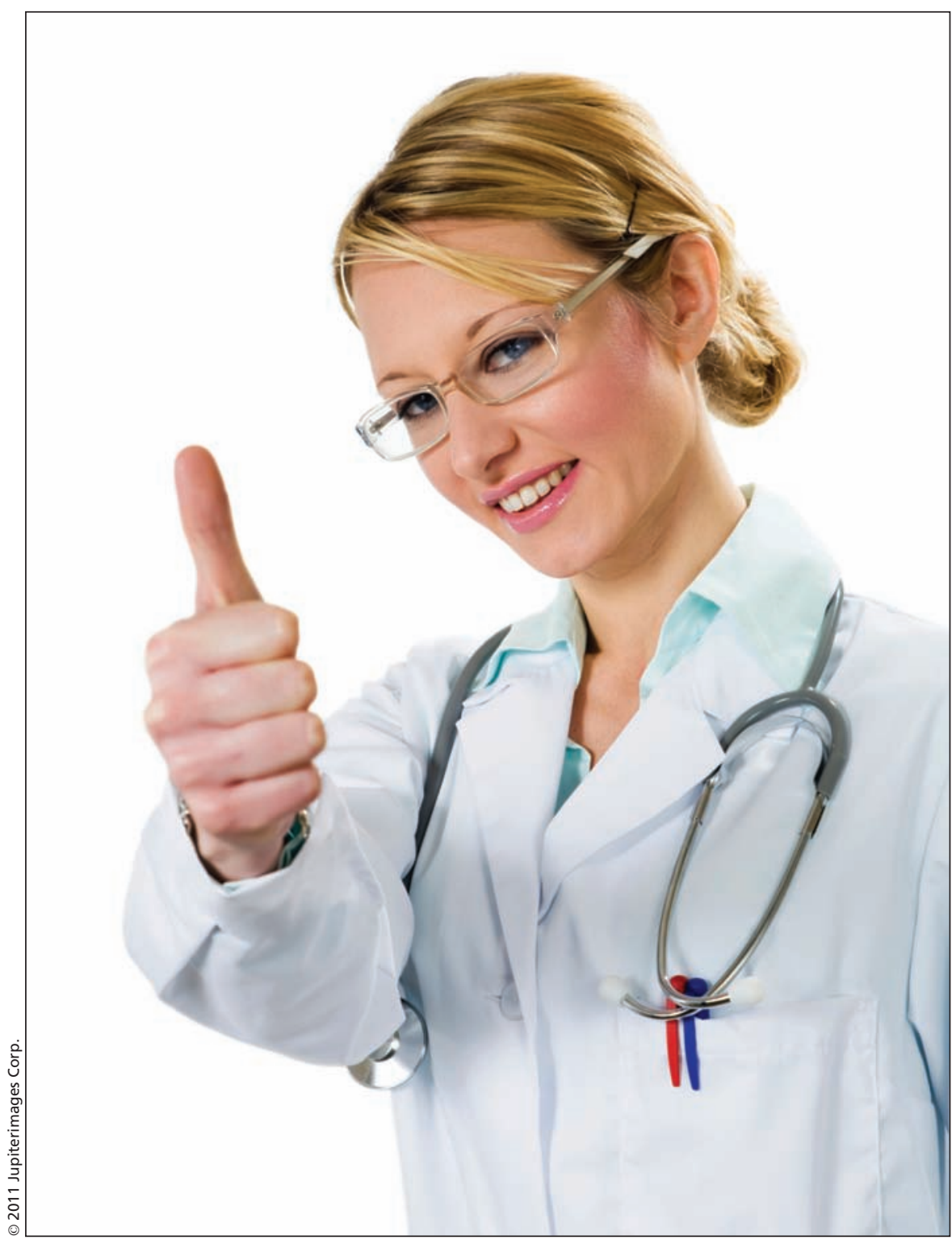

Using sign language or simply muddling through using a patient's mother tongue will no longer be acceptable in Europe under proposed reforms.

But article 53 of the directive is interpreted differently across Europe, according to regulatory reports submitted to the European Commission (http://ec.europa .eu/internal_market/qualifications/eval uation_en.htm\#additional_experience _12_2010).

Some regulators require a language assessment test post-registration (Italy).
Some subject doctors to the scrutiny of a panel (Austria), or interviews conducted by the regulator (Cyprus), while others require that doctors demonstrate that they're able to discuss a video recording with a regulatory panel (Portugal).

Some nations leave it to employers to gauge language proficiency (Ireland, Malta, Belgium, Finland, Sweden, 
Slovenia, Estonia, Latvia and Lithuania), while others require a test within the first six months of employment (some regions of Denmark).

Poland merely requires that doctors declare in writing that their level of Polish is up to speed, while Luxembourg doesn't require language assessments unless doubts are raised about a doctor's linguistic skills. Doctors in France who do not have certified proof of linguistic competency in French face language verification from the medical inspector of the department of public health, while those in the Czech Republic may face written and oral tests. Germany leaves the matter entirely in the hands of local states.

Fernando Rivas, national officer for postgraduate training for the Spanish Medical Chamber, says compulsory membership in provincial medical colleges may create a situation in which language proficiency becomes a matter easily enforced by the national chamber.
The United Kingdom's General Medical Council (GMC), meanwhile, does not conduct language assessment because its regulatory framework prohibits it.

"The GMC supports the free movement of doctors in the European Economic Area but the legal framework does not adequately protect patients. We are currently unable to assess the language and clinical skills of these doctors at registration, as we do with other doctors who qualified outside the UK, so cannot be sure that doctors on the register have the necessary language skills to practise medicine safely," Niall Dickson, chief executive of the council, writes in an email.

The council, along 25 other European medical regulators who comprise a group called Informal Network [of] Competent Authorities for Doctors, adopted a joint statement in 2010 calling on the European Commission to "examine the language provisions in the Directive to address the concerns of competent authorities in relation to language proficiency of migrant doctors in the interest of patient safety" (www .gmc-uk.org/Joint_Berlin_statement_28 _Oct_2010_37914074.pdf).

It's an indicator of a desire for tighter language requirements, Dr. Bernardo Bollen Pinto, president of the Permanent Working Group of European Junior Doctors, writes in an email. "Some regulatory bodies are expressing concerns regarding the language skills of migrating doctors and might push in the direction of mandatory language testing. This issue is particularly evident in the UK, where recent cases of alleged malpractice with disastrous results by foreign doctors came out in the media. Communication problems between doctor and patient were pointed out as the cause of the problem." - Tiago Villanueva MD, Lisbon, Portugal

CMAJ 2011. DOI:10.1503/cmaj.109-3821 